\title{
Erratum to: Rapid and environmentally-friendly extraction of carotenoids from Blakeslea trispora
}

\author{
Hong-Bo Wang $\cdot$ Li-Wei Zhang • \\ Jun Luo $\cdot$ Long-Jiang Yu
}

Published online: 2 September 2015

(C) Springer Science+Business Media Dordrecht 2015

\section{Erratum to: Biotechnol Lett \\ DOI 10.1007/s10529-015-1920-3}

Unfortunately, the supplement figure had been published as Fig. 1 in the earlier publication but it has been rectified now.

The online version of the original article can be found under doi:10.1007/s10529-015-1920-3.

\section{H.-B. Wang}

School of Life Sciences, Hubei Province Engineering

Research Center for Legume Plants, Jianghan University,

Wuhan 430056, China

L.-W. Zhang · J. Luo · L.-J. Yu ( $ه)$

Department of Biotechnology, Institute of Resource

Biology and Biotechnology, College of Life Science and

Technology, Huazhong University of Science and

Technology, Wuhan 430074, China

e-mail: 496088097@qq.com 

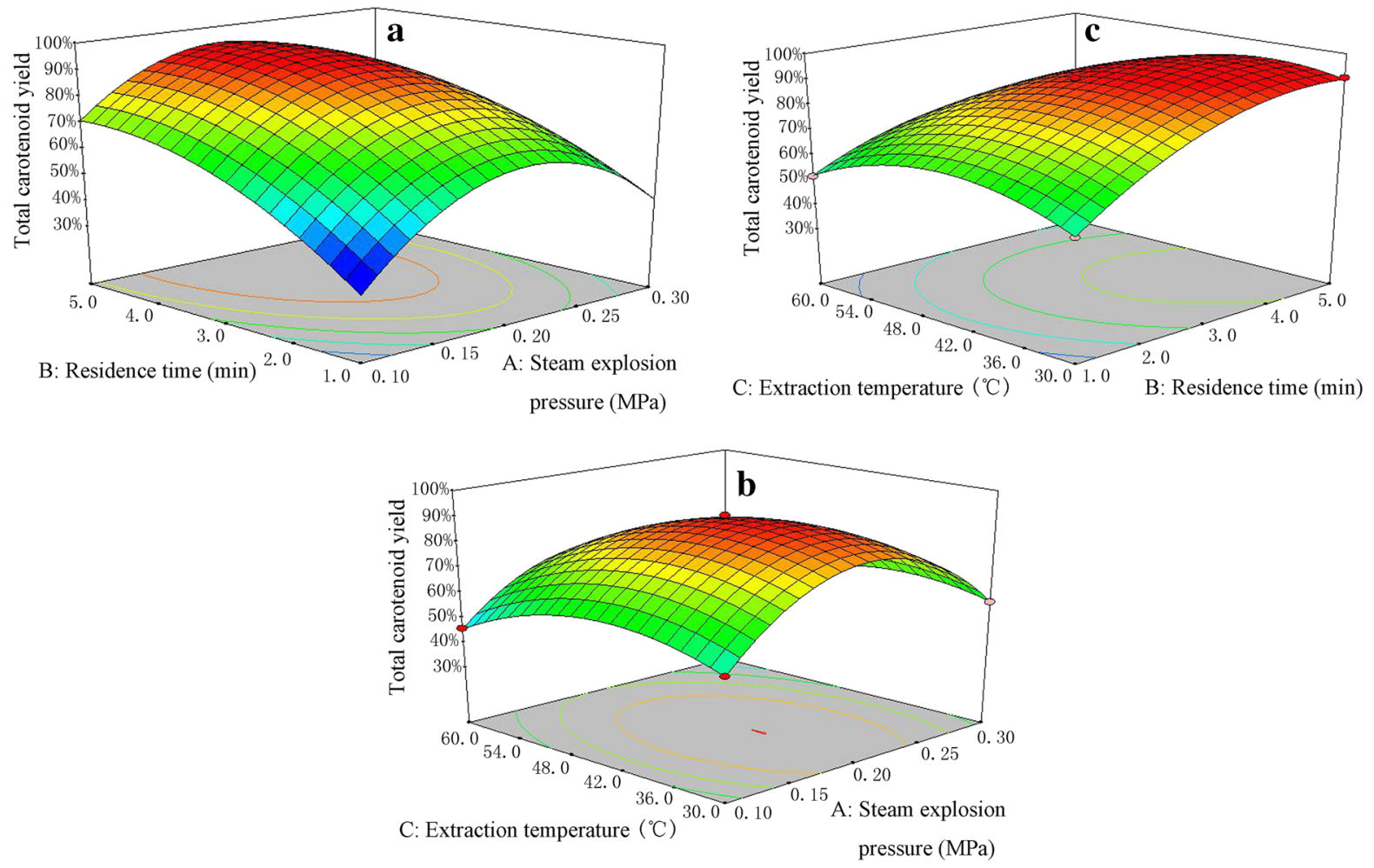

Fig. 1 Three-dimensional response surface plots for the total carotenoid yield: a effects of steam explosion pressure and residence time on the total carotenoid yield; $\mathbf{b}$ effects of steam explosion pressure and extraction temperature on the total carotenoid yield; c effects of residence time and extraction temperature on the total carotenoid yield 